\title{
A didática em Comenius e a didática contemporânea: alguns apontamentos
}

\section{Rebeca Pizza Pancotte Darius}

Pedagoga e Mestra em Educação pela Universidade Estadual de Maringá. Doutoranda em Educação pela UNESP, campus Araraquara. Coordenadora da Faculdade de Pedagogia do Centro Universitário Adventista de São Paulo UNASP, campus Engenheiro Coelho. rebeca.darius@unasp.edu.br

\section{Fábio Augusto Darius}

Historiador pela Universidade Regional de Blumenau. Mestre e Doutor em Teologia História pela Escola Superior de Teologia de São Leopoldo - EST. Professor na Faculdade de História, Mestrado Profissional em Educação e na Faculdade Adventista de Teologia (FAT) no Centro Universitário Adventista de São Paulo, campus Engenheiro Coelho. fabio.darius@unasp.edu.br 


\section{Resumo}

O presente trabalho esboça uma pesquisa acerca da Didática, objeto de estudo da Pedagogia, cujo foco é o processo de ensino. Assim, buscou-se em Comenius ${ }^{1}$, o maior pedagogo da modernidade, subsídios para compreensão da Didática como prática pedagógica e sua relação com a sociedade num todo. Analisando a obra de Comenius objetivou-se também situar o autor em seu momento histórico, qual seja, o século XVII, período de transição tardia do regime social feudal para o período pré-capitalista. Uma das principais obras que sistematizou seu pensamento educacional é a Didática Magna, que defende uma prática pedagógica necessária para aquele determinado contexto histórico e social. Ainda nesse trabalho, abordar-se-á algumas análises acerca do campo da Didática na atualidade que visam alternativas para se conceber a Didática para além das técnicas de ensinar com eficácia. Trata-se de uma área descritiva e explicativa da realidade do ensino, em que os conhecimentos teóricos e práticos estão intrinsecamente ligados.

Palavras-chave: Didática. Comenius. Ensino.

\footnotetext{
${ }^{1}$ Optou-se pela a escrita Comenius por ser a utilizada em seu livro Didática Magna e ser esta a grafia ocidental de seu nome, amplamente divulgada. Nos momentos em que foram utilizados a escrita Comênio foi em função de seu "aportuguesamento" pelos referidos autores citados.
} 


\section{Abstract}

The present work sketches a research concerning the Didactics, object of study of Pedagogy, whose focus is the teaching process. Thus, one searched in Comenius, the greatest pedagogue of modernity, subsidies for understanding the Didactics as a pedagogical practice and its relation with the society as a whole. Analyzing the work of Comenius, it was also aimed to situate the author in his historical moment, which is, century XVII, period of transistion from the late feudal social regime to the precapitalist one. One of the main works that systematized his educational thought is the Great Didactic, which approaches the pedagogical practice necessary for that particular moment according to Comenius' proposal, which will be approached in the elapsing of this study. Still in this work, one will approach some analyses concerning the field of the Didactics in the present time, which aim at alternatives to conceive the Didactics to beyond the techniques of teaching with effectiveness. It is about a descriptive and explanatory area of the reality of teaching, where the theoretical and practical knowledge are intrinsically connected.

Keywords: Didactics. Comenius. Teaching. 


\section{Introdução}

A Didática é uma área da pedagogia que trata especificamente das questões do ensino, discutida desde séculos atrás. Se tão somente a conceituarmos como "técnica de ensinar”, já encontramos em Platão (2014), talvez o primeiro dos pedagogos, algo bastante concreto em seu clássico A República, no célebre excerto hodiernamente conhecido como Mito da Caverna, a quem chama a educação "a arte do desejo" (PLATÃO, 2014, p.321).

Embora seja um tema contemporâneo, o resgate histórico é importante para compreensão de como esse campo foi sistematizado ao longo do tempo e como ele reflete em grande medida, os aspectos ideológicos, políticos, sociais, além dos educacionais, de determinado momento histórico.

É objetivo deste ensaio explorar as ideias de Comenius, pedagogo de destaque no séc. XVII, que influenciou grandemente a sociedade no início do período Moderno. As ideias de Comênio tinham cunho religioso e foram influenciadas pelo movimento da Reforma Protestante (LOPES, 2013). Seu ideário de educação foi organizado no livro Didática Magna, que propunha uma arte universal de ensinar tudo a todos, que o caracterizou como uma figura de mudança na história da pedagogia (CAMBI, 1999), já que nesse dado momento a educação formal era limitada a pequenas parcelas da população.

Pode-se dizer que a forma como se concebe a educação do homem está diretamente relacionada à forma como os homens se organizam em sociedade e isso determina, em grande medida, as características de determinado momento histórico e social. Sendo assim, a problemática envolvida nesse estudo considera como a Didática em Comenius expressa o período em que ele viveu, um período de transição, um momento em que a antiga ordem feudal da Idade Média estava sendo modificada por novos padrões de comportamento, a Modernidade e a partir disso, como esse campo de conhecimento é visto na atualidade.

Assim sendo, este texto está dividido em três partes, que correspondem aos três objetivos propostos: explicar o momento de transição na história entre a Idade Média e a Modernidade e Comenius como o principal pedagogo que expressa essa mudança em termos educacionais; compreender a Didática sistematizada por Comenius; tecer alguns apontamentos do campo da Didática na atualidade. 


\section{Contexto histórico e social de Comênio}

João Amós Comênio nasceu em 1592, em Nívnice, Morávia (hoje República Tcheca) e morreu em 1670. Aos 12 anos perdeu os pais e na ocasião da guerra dos 30 anos, por volta de 1621, fugiu devido às tropas espanholas que apoiavam a re-catolização da boêmia. Seus livros e sua casa foram queimados. Perdeu a esposa e filho, acometidos por uma praga trazida pelos soldados. Assim, em 1623 relata sua perda pessoal e estabelece sua identidade como um peregrino e afirma ter encontrado paz e contentamento não nas circunstâncias da vida, mas na fidelidade ao divino (STROOP, 2005, LOPES, 2013) .

Produziu toda sua obra no século XVII, um período de transição, em que a antiga ordem feudal da Idade Média estava sendo modificada por novos padrões de comportamento oriundos de um tempo que posteriormente denominou-se Modernidade. Para Andery (1999), a transição do sistema feudal para o sistema capitalista ocorreu ao longo de vários séculos, com uma série de conflitos e transformações no modo de viver e pensar dos homens. De acordo com Ahlert (2002, p. 73):

A cultura boêmia, do período de Hus a Comenius, buscava uma verdade individual e coletiva expressa através dos anseios de libertação religiosa, moral, nacional e social do ser humano. Essa libertação ocorreria, por um lado, pela eliminação do medo, do egoísmo e da escravidão e, por outro lado, quando o bem da humanidade fosse se estabelecer como interesse maior, a educação se tornasse permanente $\mathrm{e}$ as decisões se dessem com responsabilidade em relação aos outros.

\footnotetext{
${ }^{2}$ John Amos Comenius (Jan Ámos Komensky), Born in 1592 at Uhersky Brod in eastern Moravia in the Kingdom of Bohemia, was the youngest of five children born to Anna and Martin Komensky, [...]. From Bohemia, Comenius received a deep sense of national consciousness and pride. From the Unity of the Brethren, Comenius inherited an unshakable faith in Jesus Christ [...].

From within this milieu of homeland and faith, John Comenius envisioned a daring kind of Christianity [...]. The first of many tragedies that shaped the direction of Comeniu's life and thought was the death of both his parents when he was twelve years of age $[\ldots]$.

In 1618 decades of conflict erupted into what became known as the Thirty Years' War (1618-1648). Three years later Spanish troops in support of the re-Catholicization of Bohemia devastated Fulnek, burning Comeniu's home and books. He fled for his life to the estate of Count de Zerotin in eastern Bohemia. He never saw his wife and small son again, as they died from the plague brought to Fulnek by the soldiers. On July 31, 1627, the people of Bohemia were ordered to accept the Catholic faith or leave (STROOP, 2005, p.204).
} 
Os fundamentos econômicos não são os únicos que compõe um período de transição no regime social. "Na medida em que o regime social entra em processo de decadência, há a tendência de substituição das ideias a ele relacionadas por outras mais condizentes com o momento então vivido" (ANDERY, 1999, p.174). Eis, portanto, a urgência de um novo paradigma, agora voltado aos seres humanos enquanto seres humanos e suas vicissitudes, tempo esse que posteriormente seria percebido por Kant como Aufklärung ou iluminação, em contraste com o teocentrismo que dominou o medievo. Contrapondo o pensamento medieval de mundo fundado no teocentrismo estava se formando uma nova visão que concebia o homem como ser central, valorizando sobremaneira a sua capacidade "de conhecer e transformar a realidade" (ANDERY, 1999, p.175). Trata-se de novas descobertas também na ciência, intimamente relacionadas às necessidades geradas pelo crescimento da burguesia enquanto classe social.

A modernidade trazia consigo a ideia de ciência mais prática, ligada ao humanismo, influenciado pela Reforma, que significava uma renovação de valores, a libertação a que as pessoas estavam presas na Idade Média. De acordo com Gasparin (1994), estava se configurando uma nova forma de vida e de relações entre os homens. A crença nas suas potencialidades fizeram com que confiassem no progresso da humanidade. Novos conhecimentos eram buscados nesse período, as necessidades já não eram as mesmas da Idade Média. O homem estava formando um novo modo de produzir a vida. Aos poucos a cultura voltada unicamente para o religioso e o sobrenatural passa a desenvolver-se agora em novos moldes, fundamentando-se em fatos concretos, úteis, pragmáticos.

Trata-se do Renascimento, da volta à cultura Greco-Romana. Havia necessidade por parte da sociedade de uma educação mais prática, não tão limitada à gramática, oratória e dialética. "[...] os humanistas expressavam as transformações que o nascente capitalismo comercial impunha à estrutura econômica do feudalismo" (PONCE, 1985, p.114). Cada vez mais dava-se importância ao útil e prático na educação do novo homem e esse elemento está muito presente nos ideais de Comenius.

De acordo com Ponce (1985), o individualismo burguês exigia em termos educacionais menos disciplina, mais atenção ao indivíduo, ambiente alegre. Já em 1530, nos inícios da Reforma, escreve Lutero para que seus pais mandassem seus filhos à escola (LUTERO, 1995) São influências do movimento de libertação humanista, que 
acompanhava totalmente o desenvolvimento do comércio, o crescimento das cidades, a valorização do homem.

Nesse contexto, cita-se Lutero, cujo nome é significativo na Reforma Protestante. Esse Reformador viveu parte de sua vida no século XV e parte no século XVI. Sua vida reflete em grande medida o seu tempo, tempo de transformações econômicas e sociais (LIENHARD, 1998). Seus ideais tinham relação com o momento histórico tratado nesse texto. Ele defendia a leitura das Escrituras para seus fieis e, portanto, estes deveriam dominar a leitura e a escrita. Mas esse reformador não tinha intenção em estender os benefícios mencionados acima para toda a classe popular. Os pobres, da mesma maneira, estavam excluídos da educação formal. A esses, eram tomadas medidas paliativas de ensino do catecismo de Lutero.

De acordo com Lienhard (1998), Lutero foi influenciado pelo movimento humanista que “[...] pretendiam voltar às fontes [...] à Antiguidade clássica” (p.26). Esse movimento foi favorecido pela invenção da imprensa no século XV, que possibilitou a multiplicação dos textos impressos. O humanismo alemão era de cunho religioso preocupado com a reforma da igreja, tanto no plano moral quanto pedagógico. “[...] o cuidado acerca da pedagogia e das escolas [...] esses eram igualmente elementos constitutivos da 'filosofia' de certos humanistas” (LIENHARD, 1998, p.27).

Para Ponce (1985, p.121), "a intenção do protestantismo era, pois, educar a burguesia abonada e, ao mesmo tempo, não 'abandonar' as classes desfavorecidas”. O autor cita que em contrapartida, os jesuítas organizaram meios para se fortalecerem e não perderem a influência. As iniciativas de escolas populares da época tinham único intuito de servir como controle para cultivar espíritos mansos.

Assim, tanto a Filosofia quanto a Ciência passaram a refletir as mudanças significativas que estavam ocorrendo no âmbito econômico com as novas relações de trabalho, a emergência da classe burguesa, o capitalismo nascente (PONCE, 1985). A nova forma de trabalho que se configurava nesse período de transição da Idade Média para a Moderna, é um elemento fundamental para compreensão do pensamento educacional de Comênio. As grandes descobertas geográficas e as invenções técnicas tiveram influência direta na organização dos homens em sociedade, bem como no processo do trabalho, da produção. "Estava em curso uma revolução geral que abrangia todos os aspectos da vida humana" (GASPARIN, 1994, p.37). 
É nesse contexto que as ideias de Comenius, pastor protestante da Morávia, ganham sentido. Ele apresentou em termos educacionais as aspirações do seu tempo: trouxe à tona a questão da economia de tempo, algo já proposto e defendido pela indústria, tornando um dos aspectos principais da nova educação, educar mais em menos tempo; defendeu que as juventudes deveriam ser colocadas em contato com as próprias coisas e não com as sombras, cria, então, o Livro Ilustrado, cheio de figuras para que os alunos não apenas ouvissem, mas pudessem ver.

O século XVI, cujos movimentos exerceram grande influência no ideário educacional de Comenius (século XVII), foi um período de crise, cujos "valores e certezas tradicionais estavam sob fogo cerrado, e novos valores e certezas ainda não tinham sido encontrados" (LINDBERG, 2001, p.39).

O surgimento das cidades e uma nova mobilidade social foram também causa e consequência da passagem de uma economia natural a uma economia monetária, a uma produção dirigida ao comércio e ao desenvolvimento tecnológico (LINDBERG, 2001, p.40).

Para Saviani (2003), a sociedade moderna, também chamada de capitalista ou burguesa traz consigo a exigência de um conhecimento intelectual, uma vez que as relações não são mais naturais, mas são relações predominantemente sociais. Assim, as cidades passam a abarcar grande parte do processo produtivo e a terra já não é mais o principal meio de produção.

Desse modo, o desenvolvimento do conhecimento sistemático ganha espaço na sociedade moderna, uma vez que as condições de vida na cidade propiciam o contato com a escrita, difundida cada vez em maior escala a partir do surgimento da imprensa em meados do século $\mathrm{XV}$ e o domínio dos conhecimentos básicos tornam-se importantes para todos. É nesse momento que surge a necessidade da escolarização para todos. "Com o advento desse tipo de sociedade, vamos constatar que a forma escolar da educação se generaliza e se torna dominante” (SAVIANI, 2003, p.96).

Embora as ideias advindas da Reforma, do humanismo e renascimento se expandissem com rapidez e o crescimento da produção de livros e outros materiais impressos tenha sido tremendo, estima-se que cerca de 5\% de toda população sabia ler no início do século XVI (LINDBERG, 2001). A Reforma, de acordo com Lindberg (2001) trouxe mudanças significativas aos textos impressos. Buscando formar opiniões, o 
texto incorporava agora "figuras, imagens e caricaturas" (LINDBERG, 2001, p.52). Esse caráter visual surgido com o movimento da Reforma influenciou a produção de Comenius posteriormente, no século XVII. "Por volta de 1500, a simbiose de alfabetização e impressão cada vez mais mais difundidas, unidas a impulsos intelectuais da Renascença, estimularam um desenvolvimento sem precedentes da individualidade, bem como a formação da consciência” (LINDBERG, 2001, p.55).

Foi justamente no séc. XVII que consolida-se um modelo de pedagogia epistemológico e socialmente engajado representado principalmente por Comenius que produz uma ideia de educação universal imbuída de ideais filosóficos e políticoreligiosos. Esses ideais têm a ver com as posições dos utopistas da época renascentista, voltados aos ideais de justiça e paz. Comenius foi quem primeiro desenvolveu essas ideias no âmbito pedagógico.

Seus ideais o caracterizaram como figura de mudança na história da pedagogia, e seu trabalho foi marcado como a síntese educativa e pedagógica que acompanha o início da Modernidade. Num tempo histórico carregado de tensões, sobretudo na Europa, Comenius trabalha em prol de uma renovação tanto da cultura quanto da sociedade. Nesta renovação, a educação exerce papel criativo (CAMBI, 1999). Comênio expressa em termos educacionais o que estava acontecendo em outros ramos da esfera social, como na ciência, na cultura, nas novas formas e relações de trabalho, entre outros (GASPARIN, 1994).

De acordo com Alves (2001) com o movimento de Reforma, vários pedagogos produziram o que foi tido como referências fundamentais na história da educação. Comenius foi o maior pedagogo deste período porque concebeu a escola moderna. Para ele, o estabelecimento escolar deveria ser uma oficina de homens, em que o parâmetro de organização deveria ser as artes, termo esse (oficina de homens) que abrangia também as manufaturas.

Comenius viveu o início de um processo de renovação cultural que se desenvolveu durante os séculos XV, XVI e XVII e que teve profundas repercussões em toda a Idade Moderna. As obras de Comenius apresentam elementos tanto de uma visão Medieval, de que o homem e tudo que faz devem ser direcionados para um fim último: Deus Criador e Senhor do Universo, quanto do homem criador e centro do mundo. Ele contribuiu decisivamente para a criação de uma ciência da educação, por isso é considerado o pai da pedagogia moderna (COMENIUS, 1957). 


\title{
A didática sistematizada por Comenius: renovação educação e social
}

Pode-se dizer que 1627 foi um ano importante que marcou o pensamento de Comênio. Devido aos acontecimentos que estava vivendo nesse período, desenvolveu a linha de pensamento pedagógica. Segundo Gasparin (1994), nesse contexto, passou dos escritos especificamente religiosos aos de caráter pedagógico e político. O objetivo de Comenius foi oportunizar a todos, independente da língua ou nação, do gênero ou classe social, que saíssem da ignorância. Sua proposta era, portanto, revolucionária. Suas ideias tem influência direta do Iluminismo, motivo pelo qual acreditava na capacidade do intelecto humano (STROOP, 2005).

\begin{abstract}
A eventual renovação, devolução ou regeneração da imagem de Deus no indivíduo e na humanidade como um todo faria com que a humanidade fosse capaz de "avançar para a perfeita realização da natureza humana". Como resultado, a possibilidade do intelecto humano produzir uma mudança na natureza dos homens e mulheres deram à educação universal mais do que uma função educativa e moral - serviu como um meio missionário (STROOP, 2005, p.205)3.
\end{abstract}

Comenius defendeu a necessidade da escola, mas também teceu críticas à prática didática desenvolvida na sua época e afirmou que "as escolas podem responder positivamente ao seu objetivo formativo se forem reformadas e reorganizadas de maneira diversa" (CAMBI, 1999, p.288). Para que a educação possa se realizar de maneira satisfatória, segundo Comenius, é necessário que os professores tenham um bom método de ensino. Comenius extraiu da natureza os princípios da ordem que reina no universo, sendo esta a base do seu método.

Comênio pretendeu orientar práticas que desenvolvam as potencialidades humanas. Para ele, o instrumento capaz de efetivar isso é a didática. Assim, a educação

\footnotetext{
${ }^{3}$ The aim of Comenius's plan was "to provide opportunities, not only for all nations and tongues and orders of men, but for every single individual to rise out of the darkness of ignorance and barbarism". His revolutionary proposal was for every person in the world to be educated - male and female, all nations, and every stratum of society. The eventual renewal, return, or regeneration of the image of God in the individual and humanity as a whole meant that humankind would be able to "move towards the perfect fulfillment of human nature." As a result, the possibility of the human intellect producing a change in the nature of men and women gave universal education more than an educational or moral role - it served as a missionary means (STROOP, 2005, p.205).
} 
deve fazer desabrochar no homem as suas capacidades inatas, naturais. Ele propõe que se imite as leis da natureza, sendo esta o primeiro modelo de educação. Assim como as plantas necessitam de cuidados quando pequenas, o homem também necessita de cuidados específicos quando pequeno, e é nesse período que melhor se molda o caráter, por isso a necessidade de educá-lo (GASPARIN, 1997).

[...] Comênio mostra-se, sem dúvida, um pensador altamente interessado na democratização do ensino, contrariamente ao período em que só os filhos dos senhores feudais, ou os jovens que se dedicavam às artes liberais, ou à vida religiosa, tinham o direito de frequentar a escola (GASPARIN, 1997, p.81).

Se a nova ordem social admitia agora que todos eram considerados aptos para o trabalho, todos também eram considerados aptos para a aprendizagem escolar. Nesse sentido, a educação escolar deveria ser universal, possibilitando o ensino da instrução, da virtude e da piedade a todos.

Porém, era necessário que houvesse escolas em todos os lugares no tempo de Comênio, o que não aconteceu, era necessário investimentos e métodos adequados, e vários entraves dificultaram que suas ideias fossem totalmente colocadas em prática. Ainda assim, o educador acreditava que era possível reformar as escolas e defendeu a importância do ambiente adequado para que o professor consiga educar. Como as escolas da época não ofereciam tal ambiente, era necessário reformá-las. Utiliza o relógio como modelo, "cujo mistério consiste na ordem de suas peças, e na regularidade de suas funções" (GASPARIN, 1997, p.83).

Essa analogia também reflete o momento em que vivia, no qual era dada importância cada vez mais à maior produção em termos industriais, onde os trabalhadores eram peças que deveriam estar bem coordenadas entre si. Comenius era um homem atento ao seu tempo. Além de ver a natureza como modelo a ser seguido, também vê na invenção humana algo a ser considerado, como por exemplo, na tipografia, dizendo que da mesma maneira que é possível imprimir no papel as ciências, é possível imprimir no espírito esse mesmo conhecimento (GASPARIN, 1997).

No campo pedagógico, a base de seu pensamento está no vínculo entre os problemas da educação e os problemas gerais do homem, a educação no contexto do 
desenvolvimento social, o método universal de ensino, a instrução para todos e para toda a vida, a concepção unitária do saber, a educação para a paz (CAMBI, 1999).

Comenius defende uma educação que não faça acepção de classe social ou sexo, ou seja, que inclua a todos. Quanto ao tudo, fala da importância de se conhecer os fundamentos, as razões e os fins de todas as coisas. Dá especial destaque ao problema do saber e do ensino e o problema das escolas. Quanto ao saber, ele diz que o método deve ser completo e utilizar os momentos análise, síntese e síncrese. Quanto ao ensino, ele prevê quatro escolas: escola do seio materno, escola da virilidade, escola da velhice e escola da morte (CAMBI, 1999).

Comenius fala que o conteúdo da sua Didática será descobrir o método segundo o qual o professor ensine menos e os estudantes aprendam mais, menos enfado, menos trabalho inútil. Seu propósito era encontrar um meio pelo qual a escola pudesse ser posta em movimento.

[...] as elaborações de Comenius estão penetradas pela consciência dos condicionamentos econômicos que poderiam comprometer a expansão escolar. Essa consciência não se expressa de forma indireta, apenas, quando esse educador afirma a necessidade de a escola oferecer serviços que assegurem economia de tempo e de fadiga. Ao contrário, além dos passos já referidos, há outros elementos complementares na Didática Magna que, explicitamente, reconhecem ser elevados os custos das escolas, daí a existência de certos mecanismos econômicos de seleção de clientela (ALVES, 2001, p.85).

Assim, constata-se que esse modo de entender a educação era também o modo como a manufatura, no plano da produção econômica estava se consolidando. De modo semelhante como as transformações ocorreram na forma de produção havendo a substituição do trabalhador artesanal pelo manufatureiro com divisão de trabalho, a Didática Magna registra a passagem da necessidade histórica de superação do mestre artesanal pelo professor manufatureiro, que passou a se ocupar de uma pequena parte do extenso e complexo processo do saber. 


\title{
A Didática Magna: primeiro tratado sistemático de pedagogia. 0 que Comenius propõe?
}

De acordo com Gasparin (1994), a Didática Magna foi uma das principais obras de Comênio. Foi o primeiro tratado sistemático de pedagogia, de didática e até de sociologia escolar. Seu objetivo é mostrar como é possível ensinar tudo a todos. Segundo Comenius (1957), uma sociedade ordenada depende, em grande medida, de escolas bem ordenadas e estruturadas.

\begin{abstract}
A Didática Magna expressa bem esse momento de transição uma vez que a ousadia de Comênio foi além da perspectiva religiosa e apropriou-se das necessidades das novas forças sociais que estavam emergindo. Isso fica evidenciado a partir do título da obra, onde não propõe somente uma didática, mas uma Magna didática (GASPARIN, 1994, p.51 grifo do autor)..
\end{abstract}

Em Didática Magna, seu desejo é que todas as pessoas, as mais nobres das criaturas, por meio da didática e da educação, fossem elevadas ao grau mais alto da perfeição junto de Deus. Por isso, seu método apresenta características inexistentes nos métodos escolásticos, até então vigentes. Comenius pretendia, em seu método, ensinar com eficácia, rapidez e prazer alunos e professores para a verdadeira instrução, os bons costumes e a piedade sincera.

Segundo Gasparin (1994), para Comenius o termo didática significa tanto arte de ensinar, quanto ensino, portanto o ciclo se inicia com o ensino fecha-se com a aprendizagem. Ensinar e aprender são duas ações distintas, porém interligadas e inseparáveis. Para Comênio, o professor imprime no aluno o conhecimento como se este fosse um papel em branco ou uma tabula rasa.

$\mathrm{Na}$ Didática Magna, encontram-se implícitas e explicitas a concepção de natureza proposta por Comenius. Ele afirma que a sabedoria, a virtude e a piedade são inatas no ser humano, ou seja, o homem ao nascer traz em germe a inteligência das coisas, a harmonia e o amor de Deus. Comenius (1957) dá importância ao trabalho coletivo para a formação do homem buscando exemplos na natureza. 


\begin{abstract}
Ensinar a arte das artes é, portanto, um trabalho sério e exige perspicácia de juízo, e não apenas de um só homem, mas de muitos, pois um só homem não pode estar tão atento que the não passem desapercebidas muitíssimas coisas (COMENIUS, 1957, p.47).
\end{abstract}

O novo protótipo da arte de ensinar é uma produção, uma criação puramente humana, social, histórica. A tipografia é tomada como modelo, cuja precisão a didática deve atingir. Como a eficiência da tipografia sobre o manuscrito é muito superior em relação à arte de copiar à pena, assim seria o novo método que propunha em relação ao antigo. Seu objetivo era reformar as escolas.

\title{
DIDÁTICA MAGNA: COMO ESTÁ ESTRUTURADA
}

A Didática Magna está estruturada em quatro partes principais. A primeira parte do referido livro apresenta fundamentos teológicos e filosóficos da educação, baseado, sobretudo nas sagradas escrituras, preparação para a vida eterna (COMENIUS, 1957). Nas escolas cristãs, as Sagradas Escrituras devem ser o começo e o fim. Fala das três virtudes que deve-se aprender das Escrituras: a prática da fé, da caridade e da esperança. Todos os conhecimentos devem estar subordinados à Bíblia: Ciências, Artes, Línguas, entre outros.

A segunda parte apresenta princípios da didática em geral, a formação do homem que não deve passar a vida a aprender, mas a fazer. Comenius (1957) defendeu a democratização do ensino. Para ele, a educação deve ser universal, ou seja, deve-se ensinar tudo a todos; que se ensine a todos a conhecer os fundamentos, as razões e os objetivos de todas as coisas principais, das que existem na natureza e das que os homens fazem. O pedagogo tece críticas as escolas, por não tem corresponderem perfeitamente ao seu fim, mas podem ser reformadas, sendo o fundamento das reformas escolares a ordem de tudo.

Erram, portanto, aqueles professores que querem realizar a formação da juventude que lhes foi confiada, ditando muitas coisas e mandandoas aprender de cor, antes de a terem explicado devidamente. Erram também aqueles que as querem explicar, mas não sabem como, ou seja, não sabem como descobrir, pouco a pouco, a raiz, e nela os garfos das coisas ensinadas. E precisamente por isso estragam os alunos, como se alguém, para fazer uma fenda numa planta, em vez de uma faca, utilizasse uma bengala ou um bate-estacas. (COMENIUS, 1957, p. 218). 
A terceira parte apresenta a didática, o método para ensinar as ciências, as artes, as línguas, a moral e a piedade, embora a disciplina seja essencial para a escola, não deve alcança-la por meio de castigos (COMENIUS, 1957). Comenius elabora, na Didática Magna, diferentes métodos para se ensinar diferentes ciências. Assim, no método para ensinar as artes, por exemplo, dá ênfase à aplicação dos conhecimentos teóricos, defende o uso dos modelos, desenhos e figuras para que o aluno possa compreender.

A quarta parte do livro mostra que Comenius é o precursor da psicologia genética. Fala sobre o plano de estudos para cada fase: infância, puerícia, adolescência e juventude; a proposta é que os conteúdos sejam adaptados para os diferentes níveis; esboça o plano da escola do regaço materno, onde as crianças seriam educadas até os seis anos, recorrendo-se, a recursos audiovisuais e cita com exemplo o Livrinho de Imagens (COMENIUS, 1957).

Para a puerícia, dos seis aos doze anos, propõe a escola de línguas nacionais, reagindo contra o costume de se começar a aprendizagem da leitura e da escrita pelo latim. Aponta para que os livros devam ser adaptados à capacidade dos estudantes e a matéria deve ser apresentada de modo a desertar o interesse.

Comenius (1957) aborda a questão do tempo escolar dizendo que não se ensinará mais de quatro horas por dia: duas de manhã e duas de tarde, as horas de manhã serão consagradas a cultivar a inteligência e a memória, as de tarde, a exercícios manuais e vocais.

Para os adolescentes, dos doze aos dezoito anos, a escola de latim, quatro línguas e toda a enciclopédia das artes, o ensino das sete artes liberais: gramática, dialética, retórica, matemática, geometria, música e astronomia. Além do ensino das sete artes liberais, esta escola deve formar naturalistas, geógrafos, moralistas e teólogos (COMENIUS, 1957).

Para a juventude, dos dezoito aos vinte e quatro anos, a Academia ou Universidade que deve ser frequentada apenas pelos "gênios", os outros, para as profissões manuais, para o comércio; os cargos públicos devem ser confiados àqueles que se prepararam com sucesso (COMENIUS, 1957).

Em Didática Magna, Comenius (1957) aponta para a necessidade do desenvolvimento do intelecto, o professor precisa estar atento para as atividades que desenvolvam o raciocínio da criança e não devem despejar o conteúdo sem o explicar 
devidamente. Fazer com que o aluno decore não garante a aprendizagem, contudo, não descarta a ficção de conteúdos fundamentais.

Assim, os professores devem ser agradáveis, devem despertar admiração pelas crianças para atraí-las; a escola deve ser cheia de beleza por dentro e por fora; as regras devem estar contidas em pouquíssimas palavras, mas claríssimas e que sejam seguidas de exemplos para facilitar a compreensão (COMENIUS, 1957).

De acordo com Dahlin (2009), o pensamento de Comenius apresenta elementos tanto da antiguidade clássica de Platão e Aristóteles, como ideias modernas e tecnológicas. O conteúdo a ser ensinado deve ter utilidade para a vida, e isso se deve dar em todas as matérias: na gramática, na dialética, na aritmética, na geometria, na física, etc. O autor aponta até para as edições dos livros didáticos, que na medida do possível devem ser as mesmas.

\section{O campo da didática na atualidade: alguns apontamentos}

É preciso considerar que, como em Comenius, um projeto educativo expressa sempre um ideário mais amplo de sociedade e de homem. Como o campo da didática hoje tem refletido o momento histórico em que vivemos, bem como a luta por um ensino transformador, de emancipação das consciências? Se em Comenius isso ficou bem evidenciado, é possível identificar hoje a especificidade da Didática ligada a uma concepção de homem e sociedade desalienante?

De acordo com Gasparin (1994), faz-se urgente o retorno à Comênio, que como clássico, foi capaz de apreender as necessidades e desafios educacionais do seu tempo. Não trata-se da aplicação mecânica das suas ideias para os tempos atuais, mas sim da compreensão do seu pensamento e o complexo processo de constituição do mesmo, procurando compreender quais razões o levaram a propor uma arte universal de ensinar a todos. É desafiante buscar compreender isso porque Comênio viveu num período de transição do feudalismo para o capitalismo (do período medieval para a modernidade) em que poucos privilegiados tinham acesso ao ensino.

Segundo Gasparin (1994) a didática está presente na história dos homens porque sempre se ensinou e se aprendeu, mesmo não havendo escola. Nessa transição, o ponto de partida era uma estrutura de economia feudal que estava findando, e o pondo 
de chegada, uma incipiente economia capitalista que dava seus primeiro passos na constituição da nova estrutura da sociedade (GASPARIN, 1994, p.33).

De acordo com Caldeira e Azzi (1997) o objeto de estudo da didática é o processo de ensino-aprendizagem. Entende-se que esse processo é uma prática social, portanto, humana e intencional. No entanto, no entendimento das autoras, "a Didática carece de teorias que se aproximem do que ocorre em situações reais [...]" (p.102), porque a especificidade da aprendizagem escolar muitas vezes não são explicadas pelas teorias de aprendizagem.

Cabe, então, à Didática buscar formas de mediação entre os conhecimentos construídos pelas teorias de aprendizagem e as atividades escolares dos alunos. [...] O ponto central das discussões [...] tem girado em torno da questão da defasagem entre a formação acadêmica, proporcionada pelos cursos de licenciatura, e a realidade escolar, ou seja, entre a teoria e a prática" (CALDEIRA, AZZI, 1997, p.103 e 104).

Trata-se de um desafio para a formação de professores, que é reduzir as distâncias entre os conhecimentos teóricos e práticos, como se eles fossem antagônicos. Assim, entende-se que a Didática tem a ver com esse processo, uma vez que seu objeto de estudo é o ensino. Ele é entendido como práxis, unidade teórico-prática, que se caracteriza pela ação-reflexão-ação. A formação acadêmica do professor participa da construção dessa práxis (CALDEIRA, AZZI, 1997).

[...] o curso de Didática participa da construção da práxis docente criadora, no momento em que propicia aos alunos do curso de licenciatura a oportunidade de compreensão da prática pedagógica presente em nossas instituições escolares (CALDEIRA, AZZI, 1997, p.107).

Como campo específico de conhecimento, A Didática apresenta temas fundamentais a serem estudados:

- concepção de ensino e aprendizagem;

- intencionalidade e ação docente;

- determinantes do trabalho docente e autonomia do professor;

- sala de aula: espaço de vivências;

- avaliação e processo de ensino e aprendizagem;

- cultura, conhecimento científico, saber escolar: transposição didática (CALDEIRA, AZZI, 1997, p.114). 
Almeida (2007) entende a didática como um elemento dinâmico, um “organismo vivo" (p.11) que se modifica à medida que a sociedade vai se transformando e criando novos recursos de acessos às informações como as mídias interativas, os equipamentos de informática, entre outros. $\mathrm{Na}$ medida em que esses recursos passaram a existir, influenciaram na condução do trabalho educativo.

Assim, a didática está presente em todo conteúdo ensinado e é necessário compreender como as aprendizagens se desenvolvem na realidade atual, uma vez que a didática trata diretamente das relações entre ensino e aprendizagem. Trata-se de uma “concepção multiforme e ininterrupta” (ALMEIDA, 2007, p.11) da didática.

É importante considerar, segundo Almeida (2007), a possível distância entre os conhecimentos científicos e os escolares, sendo necessário a transformação do conhecimento numa linguagem mais próxima daquela que os alunos utilizam, sem contudo diminuir a sua qualidade ou importância. Para tanto, é fundamental estabelecer claramente o conteúdo, ou seja, o objeto a ser ensinado, sem perder de vista a totalidade.

No entanto, nas palavras de Franco e Pimenta (2016), a transposição didática não é o único aspecto que deve ser foco de atenção das investigações nessa área, mas sim as articulações possíveis entre uma didática fundamental e as didáticas específicas, sendo estas últimas, "[...] metodologias voltadas à estruturação da parte do ensino que organiza os conteúdos das diferentes disciplinas" (FRANCO; PIMENTA, 2016, p.543). A prática pedagógica é complexa e para compreensão da mesma é necessário mais que transposição didática, ou seja, a transformação dos conteúdos científicos em escolares. $\mathrm{O}$ ensino transcende a estrutura metodológica e conceitual dos conteúdos, isso porque:

[...] a questão da Didática amplia-se e complexifica-se ao tomar como objeto de estudo e pesquisa não apenas os atos de ensinar, mas o processo e as circunstâncias que produzem as aprendizagens e que, em sua totalidade, podem ser denominados de processos de ensino. Portanto, o foco da Didática, nos processos de ensino, passa a ser a mobilização dos sujeitos para elaborarem a construção/reconstrução de conhecimentos e saberes.

Assim, mais complexa que elaborar o ensino, numa perspectiva antiga de organização de transmissão de conteúdos, será agora a perspectiva de desencadear nos alunos atividade intelectual que lhes permita criar sentido às aprendizagens e, só assim, reelabora-las e transformá-las em saberes (FRANCO; PIMENTA, 2016, p.541). 
$\mathrm{Na}$ formação dos futuros professores em cursos de licenciatura é necessário a aproximação do acadêmico com a realidade escolar fazendo análise da prática docente. Essa análise aponta dois caminhos que precisam ser percorridos: buscar a teoria que ajude a compreender a realidade e aproximar-se da prática efetiva. Assim, sabe-se que toda prática não é neutra, mas revela em si uma postura teórica e política, consciente ou não. De acordo com Pimenta e Anastasiou (2005, p.42) “a área da Pedagogia que tem por objeto de estudo o ensino é a Didática” e se já em Comênio (séc. XVII) na obra Didática Magna abriu caminho para esse campo específico de conhecimento, hoje faz-se necessário discussões e estudos acerca dessa área.

Se lembrarmos que à escola pública ampliada do século XX afluíram as crianças das camadas sociais até então dela excluídas, essa "naturalização" do ensino e a valorização do método único de ensinar acabaram por consolidar a didática como uma forma de exclusão social (PIMENTA, ANASTASIOU, 2005, p.45).

Nesta perspectiva, “à Didática, então, caberia dispor aos futuros professores os meios e os instrumentos eficientes para o desenvolvimento e o controle do processo de ensinar" (PIMENTA, ANASTASIOU, 2005, p.46). Não caberia, portanto, à didática questionar os fins do ensino. Esse pensamento está presente nos cursos de licenciatura, onde se espera uma saída única para os problemas educacionais, um método, uma técnica capaz de ensinar com eficiência. Esquece-se que "[...] a tarefa da Didática é a de compreender o funcionamento do ensino em situação, suas funções sociais, suas implicações estruturais [...]” (PIMENTA, ANASTASIOU, 2005, p.48).

A demanda atual para a educação tem mostrado que "[...] para além das preocupações com as técnicas de ensinar e da avaliação, o campo da Didática oferece inúmeras outras possibilidades à docência universitária" (PIMENTA, ANASTASIOU, 2005, p.51). As pesquisas recentes em Didática, cujas situações práticas de sala de aula e os contextos escolares são objetos de investigação fazendo ligações com as teorias didáticas e pedagógicas, destacam a análise de temas clássicos da Didática como avaliação, metodologias, relação comunicacional e técnicas, ensino e aprendizagem (PIMENTA, ANASTASIOU, 2005).

Os professores universitários, quando indagados acerca do que esperam da Didática, são unânimes em afirmar: as técnicas de ensinar 
- mesmo porque, de uma forma ou de outra, aprenderam a ensinar com sua experiência e mirando-se em seus próprios professores. (PIMENTA, ANASTASIOU, 2005, p.62).

As autoras questionam qual seria então o sentido de se ensinar Didática. Recebendo críticas ferozes na década de 80 devido ao seu caráter instrumentaltecnicista, com ausência de bases científicas, sem objeto e conteúdos próprios e questionada devido à pretensa neutralidade, o Seminário A Didática em Questão, (PUC-RJ, 1982), apresentou elementos de superação seja da negação ou exaltação da Didática, situando-a, segundo Luckesi (1983), como um modo crítico de desenvolver uma prática educativa emancipadora.

A Didática, neste período histórico, deveria contribuir para a democratização do ensino público, colocando os professores em condições de ensinar as crianças até então excluídas e que passaram a ter acesso à escola a partir dos anos 60. "Assim, a atividade de ensinar dos professores nos contextos historicamente situados constitui o cerne da ressignificação da Didática e da profissão docente" (PIMENTA, ANASTASIOU, 2005, p.72). De acordo com elas, a Didática faz parte da identidade docente, e esta é construída a partir do significado social que o docente atribui à profissão, bem como à educação escolar.

O professor universitário tem um campo específico de conhecimentos. No entanto, além do domínio do conhecimento, ele necessita refletir sobre questões inerentes à sua profissão docente, cujo significado é social. Então, é necessário questionar a si mesmo sobre o significado que esses conhecimentos que irá ensinar tem na sociedade contemporânea e na vida dos jovens alunos dos quais serão professores.

Educar na universidade significa ao mesmo tempo preparar os jovens para se elevarem ao nível da civilização atual, de sua riqueza e de seus problemas, a fim de que aí atuem [...] a finalidade da educação escolar na sociedade tecnológica, multimídia e globalizada, é possibilitar que os alunos trabalhem os conhecimentos científicos e tecnológicos, desenvolvendo habilidades para operá-los, revê-los e reconstruí-los (PIMENTA, ANASTASIOU, 2005, p.81).

Ao se tratar de ensino, sabe-se que os conhecimentos específicos das áreas e a experiência são importantes, mas não suficientes. É imprescindível os saberes do campo da didática e da pedagogia. Assim, “[...] à Didática contemporânea compete proceder a 
uma leitura crítica da prática social de ensinar, partindo da realidade existente e fazendo um balanço das iniciativas que enfrentam o fracasso escolar" (PIMENTA, ANASTASIOU, 2005, p.83).

Os saberes pedagógicos podem colaborar com a prática. Sobretudo se forem mobilizados em decorrência dos problemas que a prática apresenta, entendendo, assim, a dependência da teoria em relação à prática, pois esta lhe é anterior. (PIMENTA, ANASTASIOU, 2005, p.86).

Segundo Pimenta (2006), a educação enquanto prática social é responsável pela "humanização dos homens" (p.84), para que os mesmos possam usufruir de todo progresso que a humanidade conquistou como resultado do trabalho. A pedagogia estuda as diferentes maneiras pelas quais a educação se converte em prática social intencional. E é justamente nessa área, no estudo dos diferentes modos que a educação se manifesta que entra a Didática, cujo objetivo é trabalhar especificamente a "finalidade prática da educação" (p.84), que envolve diretamente o trabalho do professor no processo de ensino-aprendizagem.

A pedagogia é entendida como atividade teórica, uma vez que envolve conhecer a realidade e estabelecer finalidades, e a educação seria a atividade prática propriamente dita, ou seja, a práxis (PIMENTA, 2006). Quanto à especificidade da Didática, diz-se que:

é garantida pela preocupação com a compreensão do processo de ensino-aprendizagem e a busca de formas de intervenção na prática pedagógica. A Didática tem por objetivo o "como fazer", a prática pedagógica, mas este só tem sentido quando articulada ao "para que fazer"e ao "por que fazer" (CANDAU, 1983, p.121).

Segundo Pimenta (2006), a Pedagogia enquanto ciência não produz transformações na realidade. Essas transformações são possíveis pela ação dos educadores na sua práxis (atividade teórico-prática) e só por meio de uma ação transformadora é possível que a educação leve o homem à humanização.

De acordo com Libâneo (2004), a Didática investiga como auxiliar os alunos a desenvolverem a capacidade do pensar. Assim, na escola, devem "aprender a cultura e internalizar os meios cognitivos de compreender e transformar o mundo”. (LIBÂNEO, 2004, p.5). Para esse autor, essa disciplina precisa acompanhar as investigações quanto o 
aprender e ensinar e sobre o papel do professor como mediador. Isso porque desenvolver o pensamento do aluno pressupõe que o professor utilize metodologias e procedimentos adequados, uma vez que, como mediador do processo, está entre o aluno e o conhecimento no processo educativo.

[...] trata-se de saber o que e como fazer para estimular as capacidades investigadoras dos alunos, ajudando-os a desenvolver competências e habilidades mentais. Em razão disso, uma didática a serviço de uma pedagogia voltada para a formação de sujeitos pensantes e críticos deverá salientar em suas investigações as estratégias pelas quais os alunos aprendem a internalizar conceitos, competências e habilidades do pensar, modos de ação que se constituam em "instrumentalidades" para lidar praticamente com a realidade: resolver problemas, enfrentar dilemas, tomar decisões, formular estratégias de ação (LIBÂNEO, 2004, p.7).

Neste sentido, Libâneo (2004) concebe o ensino como uma forma de organização da cultura tanto material quanto espiritual produzido pelo homem, sendo este visto como ser social. Pimenta (2006) propõe alguns questionamentos que envolvem a questão da Didática: como entender o processo ensino-aprendizagem de maneira dialética? Como investigar esse processo tendo em vista a desalienação? Como identificar nesses processos a possibilidade de humanização dos homens? De acordo com a autora supracitada, não há respostas prontas, mas "configuram o próprio movimento histórico de construção/reconstrução da Didática como área de conhecimento" (PIMENTA, 2006, p.108), o que está diretamente ligado com a existência e função da escola nessa sociedade.

A tensão didática entre o existente e o necessário está no cerne da investigação didática, sustentada por seu compromisso com a prática de orientar o desenvolvimento científico para que o processo de ensino-aprendizagem seja um dos instrumentos sociais da desalienação [...] (PIMENTA, 2006, p.110).

Para finalizar esse estudo, embora ele possibilite outras inúmeras discussões, considera-se necessário voltar a Comenius para fazer um paralelo com as ideias acima discutidas. Sabe-se que Comenius viveu no século XVII na Europa, num momento de transição de um regime social para outro, em que novos valores estavam sendo 
formados. Diante disso, conseguiu expressar, em termos pedagógicos, a necessidade de sua época, propondo um método para ensinar tudo a todos.

Em tempos atuais, percebe-se a preocupação, por parte dos estudiosos da educação, com a necessidade dos educadores terem os conhecimentos didáticos, pois do uso de tais conhecimentos depende, em grande medida, um bom ensino e consequentemente, a aprendizagem.

Diferentemente do tempo de Comenius, hoje não se fala em democratização do ensino em função de convicções religiosas, mas sabe-se que a necessidade do conhecimento científico chegar às classes menos favorecidas continua sendo urgente em nossos dias. Essa necessidade é comparada àquela, onde a maioria da população não sabia ler nem escrever, uma vez que hoje a questão não é o acesso à escola em si, mas se a escola tem garantido a aquisição dos conhecimentos necessários à vida em sociedade.

Outra questão pertinente é que não basta ao professor ter posse dos conhecimentos científicos. Ao ensinar, necessita mobilizar outros conhecimentos do campo da pedagogia, onde situamos a didática. Daí a importância dos cursos universitários de formação de docentes, por meio dos professores universitários, propiciarem uma formação para além das técnicas ou teorias, que consiga atrelar teoria e prática numa práxis transformadora.

Assim, entende-se também que o ensino da Didática está totalmente vinculado à problemática da educação na sociedade. Entende-se que existe uma relação estreita entre educação e sociedade, na qual a escola é influenciada e influencia por meio do seu âmbito próprio de atuação.

\section{Considerações Finais}

As reflexões desenvolvidas neste trabalho acerca de Comenius - objeto desse estudo - possibilitaram reflexões imprescindíveis para compreensão das práticas pedagógicas, tanto no século XVII - período em que Comenius produziu - quanto nos dias atuais. A reflexão sobre as ideias de Comenius, relacionadas ao momento histórico em que viveu podem nos dar base para compreensão das práticas pedagógicas desenvolvidas nos dias atuais em relação ao momento histórico em que vivemos. Considera-se que não há uma relação direta, mas pode-se compreender que as 
necessidades postas aos homens fazem com que estes produzam novos conhecimentos para satisfazer tais necessidades.

Assim, no período em que Comenius viveu havia necessidade que a leitura e a escrita atingisse camadas da sociedade até então privadas desse conhecimento. Isso porque um novo mundo estava nascendo, novas ideias advindas do renascimento, iluminismo, reforma protestante, novo sistema de produção, nova economia, enfim, era necessário que mais pessoas soubessem pelo menos o mínimo para que a nova ordem social avançasse.

No entanto, sabe-se que as ideias de Comenius não foram colocadas em prática na sua totalidade devido à várias questões de ordem estrutural: falta de prédios escolares para todos, falta de professores capacitados, falta de conhecimento do método que propunha, entre outros. Apesar disso, suas ideias influenciaram a pedagogia de forma decisiva, como apontamos no decorrer dos capítulos um e dois deste trabalho, que o levou a ser chamado de pai da pedagogia moderna.

$\mathrm{Na}$ atualidade, são inúmeras as discussões acerca da Didática, e como essa área do conhecimento vem se configurando nas últimas décadas, e a crescente necessidade de atrelar conhecimentos teóricos aos práticos. Assim, busca-se uma Didática hoje que corresponda às demandas da sociedade atual, possibilitando aos professores o como ensinar, por meio da ação-reflexão-ação, pela apreensão das necessidades posta aos homens hoje, que indicarão como agir, como fazer do ensino uma possibilidade de transformação.

\section{Referências}

AHLERT, Alvori. O mundo de Comenius: entre conflitos e guerras, uma luz para a prática pedagógica - Quatrocentos e dez anos do nascimento do autor da Didática magna. Estudos Teológicos, v. 42, n.3, p.70-79, 2002.

ALMEIDA, Geraldo Peçanha de. Transposição didática: por onde começar? São Paulo: Cortez, 2007.

ANDERY, Maria Amália Pic Abib. Et al. Para compreender a ciência: uma perspectiva histórica. 8.ed. - Rio de Janeiro: Espaço e Tempo; São Paulo: EDUC, 1999. 
ALVES, Gilberto Luiz. A produção da escola pública contemporânea. Campo Grande, MS: Ed. UFMS; Campinas, SP: Autores Associados, 2001.

CALDEIRA, A. M. S.; AZZI, S. Didática e construção da práxis docente: dimensões explicativa e projetiva. In: Alternativas no ensino de didática. 9. ed. Campinas, SP: Papirus, 1997, cap. 5, p. 97-128.

CAMBI, F. História da pedagogia. Tradução de Álvaro Lorencini. - São Paulo Fundação Editora da UNESP (FEU), 1999.

CANDAU, V. M. (org.) A didática em questão. Petrópolis, RJ: Editora Vozes, 1983.

COMENIUS. João Amós. Tratado da arte universal de ensinar tudo a todos. Tradução de Joaquim Ferreira Gomes. 3. ed. Praga: Fundação Calouste Gulbenkian, 1957.

DAHLIN, B. Education and psycho-utopianism: Comenius, Skinner, and Beyond. World Futures: The Journal of General Evolution 65, no 7 (october 2009): p.507-526. Academic Search Premier, EBSCOhost. (accessed november 18, 2010).

FRANCO, M. A. S.; PIMENTA, S. G. Didática multidimensional: por uma sistematização conceitual. Educação e Sociedade, Campinas, v. 37, no. 135, p.539-553, abr.-jun., 2016.

GASPARIN, J. L. Comênio ou da arte de ensinar tudo a todos. Campinas, SP: Papirus, 1994. Comênio - a emergência da modernidade na educação. Petrópolis, RJ:

Vozes, 1997.

LIBANEO, José Carlos. A didática e a aprendizagem do pensar e do aprender: a teoria histórico-cultural da atividade e a contribuição de Vasili Davydov. Rev. Bras. Educ. [online]. 2004, n.27, pp. 5-24. ISSN 1413-2478. http://www.scielo.br/pdf/rbedu/n27/n27a01.pdf. Acesso em 28 de jun. 2010

LIENHARD, M. Martinho Lutero: tempo, vida e mensagem. São Leopoldo: Sinodal, 1998. 
LINDBERG, C. As reformas na Europa. São Leopoldo: Sinodal, 2001.

LUTERO, M. Obras Selecionadas. São Leopoldo: Sinodal; Porto Alegre: Concórdia, vol.5, 1995.

LOPES, Edson Pereira. Espiritualidade protestante no pensamento de João Amós

Comenius. Rev. Pistis Prax., Teol. Pastor. Curitiba, v. 5, n. 1, p. 233-251, jan./jun. 2013

PIMENTA, S. G. O estágio na formação de professores: unidade teoria e prática? - 7.ed. São Paulo: Cortez, 2006.

PIMENTA, S. G; ANASTASIOU, L. G. C. Docência no ensino superior. 2. ed. São Paulo: Cortez, 2005, cap. 1, p.35-92.

PLATÃO. A República. 14a ed. Porto: Calouste Gulbenkian, 2014.

PONCE, A. Educação e luta de classes. Tradução de José Severo de Camargo Pereira. 5. ed. São Paulo: Cortez: Autores Associados, 1985.

SAVIANI, D. Pedagogia histórico-critica: primeiras aproximações. 8. ed. Revista e ampliada. - Campinas, SP: Autores Associados, 2003.

STROOP, M. W. The legacy of John Amos Comenius. International Bulletin of Missionay Research 29, no4, p.204-208. Academic Search Premier, EBSCOhost, 2005. 